\title{
Prolactinoma in Some Ménière's Patients - Is Stress Involved?
}

\author{
Kathleen C. Horner, Ph.D., Régis Guieu, M.D., Jacques Magnan, M.D., André Chays, M.D., \\ and Yves Cazals, Ph.D.
}

\begin{abstract}
Dizziness is a common complaint in primary care clinics and can enter the diagnostic profile of different pathologies spanning from psychiatric problems to vestibular dysfunction. Episodes of vertigo in Ménière's patients are often reported to be triggered by stress but no physiological data are available to account for the subjective link. The study involved 42 Ménière's patients hospitalized for neurectomy of the vestibular nerve for relief of incapacitating vertigo. In addition 18 patients with neurinoma of the vestibular nerve and 12 patients with facial spasm, who underwent surgery, served as controls. A blood sample was taken on the day of surgery in order to
\end{abstract}

determine the level of battery of different stress hormones. The most striking observation was the presence of hyperprolactinemia (above $20 \mu \mathrm{g} / \mathrm{l}$ ) in 14 Ménière's patients. The presence of prolactinoma was confirmed by MRI in six cases out of six investigated and the others have not yet been followed up in this retrospective study. These observations are clearly indicative for systematic determination of prolactin levels before opting for surgery in Ménière's patients.

[Neuropsychopharmacology 26:135-138, 2002] (C) 2001 American College of Neuropsychopharmacology. Published by Elsevier Science Inc.
KEY WORDS: Stress; Vertigo; Hearing; Tinnitus; Prolactin; Dopamine

Vertigo is episodic dizziness, considered as an imbalance originating within the vestibular system (Baloh 1998). Peripheral vestibulopathologies, (including benign positional vertigo, Ménières disease, vestibular neuritis, labyrinthitis) can account for $35-55 \%$ of patients, psychiatric disorders for 10-25\%, cardiovascular disease $5 \%$, and brain tumors less than $1 \%$ while $10 \%$

From the Laboratoire d'Otologie (KCH, YC), Cnrs UMR 6560 (RG), Service ORL (JM, AC), Hôpital Nord, Marseille, France.

Address correspondence to: Kathleen C. Horner, Laboratoire d'Otologie, Inserm EPI9902 Université de la Méditerranée, AixMarseille II, Faculté de Médecine, Boulevard Pierre Dramard, 13916 Marseille Cedex 20, France. Tel.: +04 9169 89 46, Fax: +04 916987

31, E-mail: horner.k@jean-roche.univ-mrs.fr

Received May 5, 2001; revised June 18, 2001; accepted June 26, 2001.

Online publication: $7 / 5 / 01$ at www.acnp.org/citations/ Npp070301143. elude diagnosis (Hoffman et al. 1999). We were particularly concerned with Ménière's patients who present vertigo together with fluctuating hearing loss and tinnitus. The cause of this inner ear dysfunction is not known. It starts as monolateral and evolves to bilateral in $30-50 \%$ of patients (Paparella 1991). In cases of incapacitating vertigo, selective surgery involving neurectomy of the vestibular nerve can be opted for, when no other medical approach has succeeded.

Emotional stress has long been known to be a precipitating factor and a psychosomatic aspect of Ménière's disease is one factor, which has long been recognized (Fowler and Zeckel 1952). The association between "dizziness" and "psychiatric dysfunction" has recently come to the forefront of medical discussion (Yardley et al. 1998, 1999; Moss-Morris and Petrie 1999). One unique time-series analysis based on self-assessment, on stress and symptoms of Ménière's disease clearly associated stress with symptoms and in particular with vertigo in 13 out of 20 patients (Andersson et al. 1997). 
It seemed timely to investigate some objective measure of stress and to this end we investigated the level of a battery of stress hormones.

\section{METHODS}

This study was carried out over a period of two years. The patients were recruited from the Department of Otolaryngology where they had been classified as Ménière's patients with various degrees of hearing loss, tinnitus, and incapacitating vertigo, and fitted the guidelines for the diagnosis of Ménière's disease as defined by the Committee on Hearing and Equilibrium of the American Academy of Otolaryngology - Head \& Neck Surgery (Committee on Hearing and Equilibrium 1995). The patients underwent surgery to relieve incapacitating vertigo, which in all cases handicapped their private and professional lives and which in $60 \%$ of the cases rendered driving a vehicle difficult or impossible.

A total of 16 males and 26 females had all been scheduled for and underwent neurectomy of the vestibular nerve. Before surgery a final audiogram was determined and vestibular function was assessed by videonystagmography as well as dynamic posturography. Since the level of stress hormones might be acutely biased by the anxiety of surgery, we included patients with acoustic neurinoma ( $\mathrm{n}=18 ; 5$ males, 13 females) and with facial spasm ( $\mathrm{n}=12 ; 5$ males, 7 females) who were also scheduled for a similar surgical approach, for comparison. The age ranges were similar as presented in Figure 1.

A blood sample was taken on the morning prior to surgery and pre-medication. The blood was drawn into dry vacuum tubes for all hormones except for adrenocorticotrophic hormone (ACTH) which was collected in tubes containing EDTA immediately chilled and sent to the biochemistry laboratory for processing. The samples were centrifuged at $2500 \mathrm{G}$ for $10 \mathrm{~min}$ and supernatants frozen at $-80^{\circ} \mathrm{C}$ for later analysis. Concentrations of cortisol, prolactin, ACTH, growth hormone $(\mathrm{GH})$, and $\beta$-endorphin-like immunoreactivity $(\beta$-ELI) were analyzed.

None of the patients was taking medication, which could have influenced the level of stress hormones.

\section{RESULTS}

Within the battery of stress hormones investigated the different hormones showed variability between subjects. The data are summarized in Table 1. The most systematic and striking result concerned the level of prolactin and those data were fully analyzed and presented here. Within the group of Ménière's patients, the level of prolactin was above the reference normal level

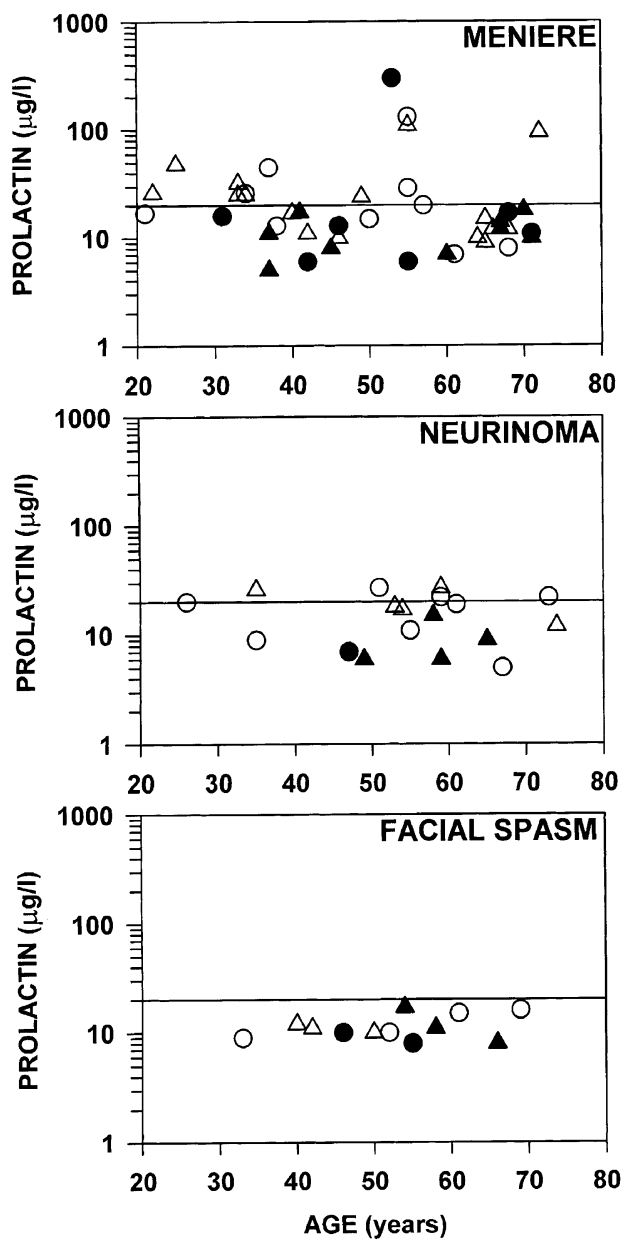

Figure 1. The serum level prolactin $(\mu \mathrm{g} / \mathrm{l})$ in the patient sample is presented as a function of age (years). Ménière's disease ( $n=42)$; patients with neurinoma $(n=18)$; and patients with facial spasm $(n=12)$. The males are represented by black symbols and 16 females by open symbols. Right ear is indicated by a circle and left ear by a triangle. The upper normal limit for prolactin is $20 \mu \mathrm{g} / 1$.

$(20 \mu \mathrm{g} / \mathrm{l})$ in 14 cases. In contrast the level of prolactin was within the normal range in all patients with facial spasm and only slightly elevated in four patients with neurinoma. The presence of prolactinoma was confirmed by MRI in six out of six Ménière's patients investigated. The other cases could not yet be followed up, principally because of the retrospective nature of this study.

The bilateral audiograms of the Ménière's patients with prolactin levels greater than and less than $20 \mu \mathrm{g} / 1$ are presented in Figure 2 and Figure 3 respectively. To facilitate the presentation the patient data were regrouped arbitrarily into two groups: over and under 50 years old. The data suggest that when prolactin was elevated there was better preservation of hearing in the non-operated ear (Figure 2, right column) compared with those cases when prolactin was within the normal 
Table 1. Mean and/or (min-max) Values for Measured Parameters

\begin{tabular}{lccccc}
\hline & Prolactin $(\mu \mathrm{g} / \mathbf{l})$ & Cortisol $(\mu \mathrm{g} / \mathbf{l})$ & ACTH $(\mathbf{n g} / \mathbf{l})$ & GH $(\mu \mathbf{g} / \mathbf{l})$ & B-endorph. $(\mathbf{n g} / \mathbf{l})$ \\
\hline Standard ref. & $(2.7-17)$ & $(50-250)$ & $<46$ & $<8.7$ & $<20$ \\
Ménière & $30.2(5.2-304)$ & $103(5-32)$ & $19.7(8-74)$ & $0.7(0.05-4.6)$ & $22(5-40)$ \\
Neurinoma & $15.5(4.8-27)$ & $80.8(20-190)$ & $15.3(7-56)$ & $1.4(0.05-11.1)$ & $11.7(5-15)$ \\
Facial spasm & $11.3(7.7-17)$ & $81.3(11-212)$ & $29.8(9-108)$ & $0.8(0.03-4.7)$ & n.a. \\
\hline
\end{tabular}

range (Figure 3, right column). However, the presentation of the audiogram data according to age is biased by the fact that high-prolactin group included patients mostly between 50 and 60 years old while the normal prolactin group included patients mostly between 60 and 70 years old. The high frequency loss might be compounded by age-related presbyacusis.

\section{DISCUSSION}

We investigated the level of a battery of stress hormones in a sample of 42 Ménière's patients with incapacitating vertigo. The essential finding is that prolactin was abnormally elevated in 14 patients and prolactinoma con-

MENIERE - PROLACTIN $>20 \mu \mathrm{g} / \mathrm{l}$
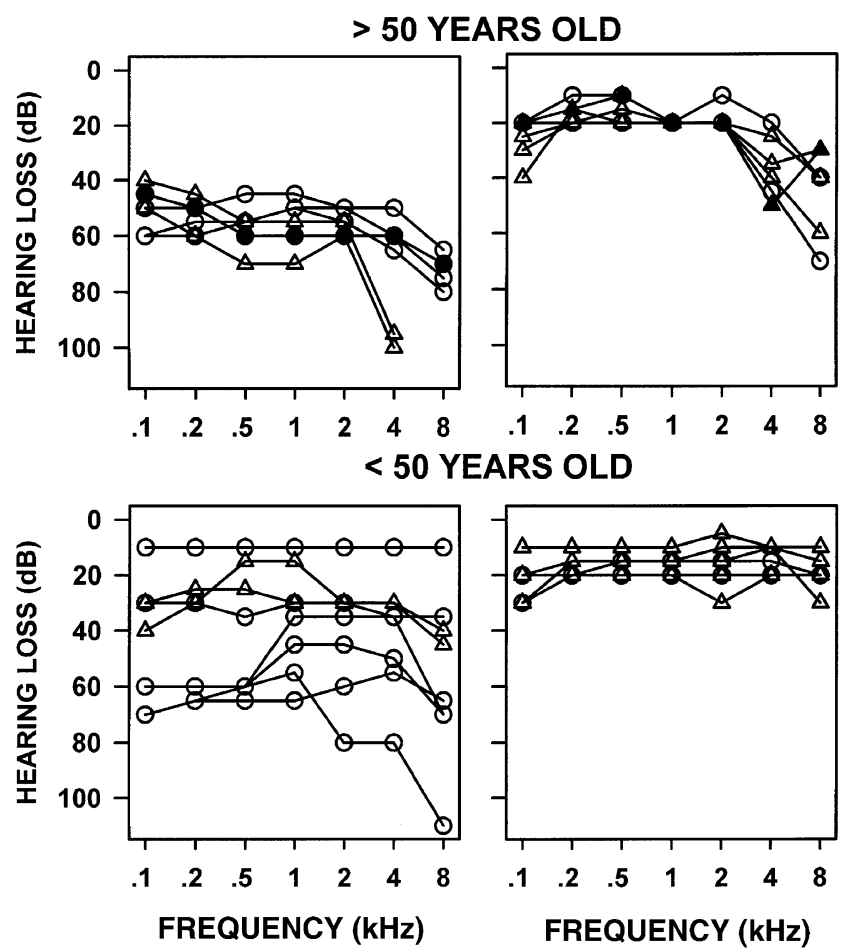

Figure 2. Bilateral audiograms from the Ménièe's patients with prolactin level above the normal range. The audiogram for the operated ear is presented in the left column and the nonoperated ear in the right column. firmed in six out of six investigated. The patients with hyperprolactinemia represents a surprisingly high percentage, close to $30 \%$ (and at least $15 \%$ with prolactinoma) in our limited sample of patients, which was neither filtered nor selected. In particular the prevalence of hyperprolactinemia is reported to be $0.4 \%$ in an unselected normal population (Biller et al. 1999).

Although prolactinomas have been reported to be associated with tinnitus and fullness of the ear (Dominguez Ugidos et al. 1998) with vertigo (Schaller et al. 1998) and with hearing loss as well as vertigo (Blagoveshchenskaia and Leushkina 1988), the presence of the prolactinomas in our sample of patients had been ignored. Clearly our data demonstrate that a sub-cate-

MENIERE - PROLACTIN $<20 \mu \mathrm{g} / \mathrm{l}$
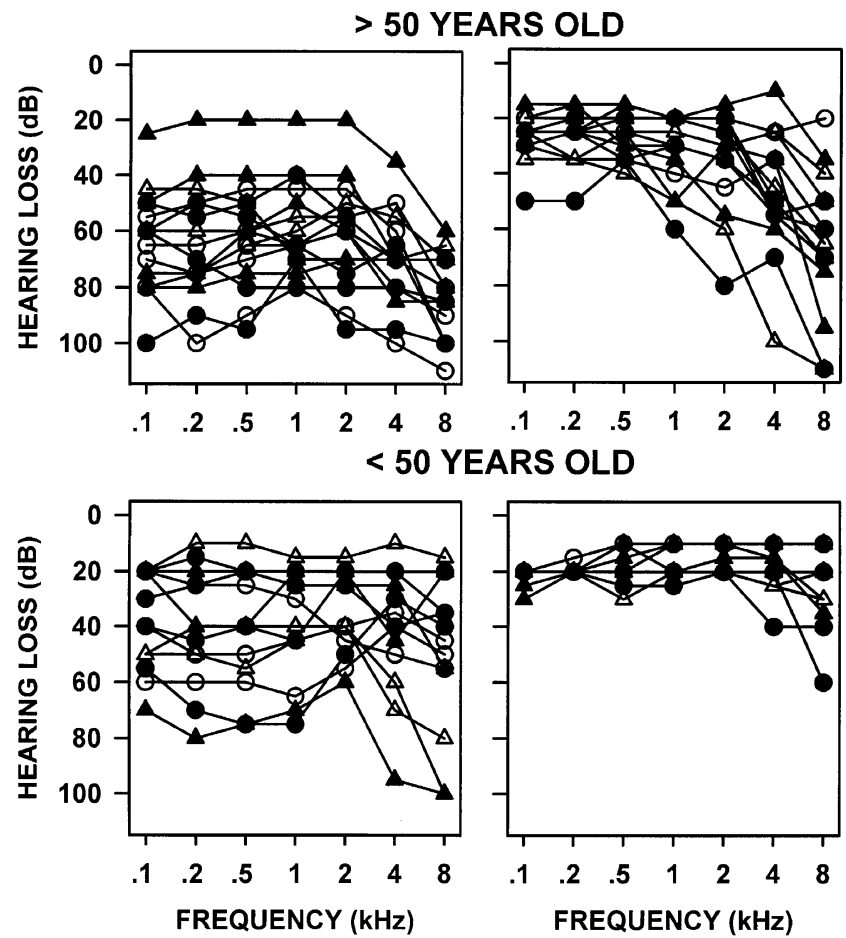

Figure 3. Bilateral audiograms from the Ménière's patients with prolactin level within the normal range. The audiogram for the operated ear is presented in the left column and the non-operated ear in the right column. 
gory of Ménière's patients can present hyperprolactinemia and prolactinoma.

It is known that stress can contribute to hyperprolactinemia (Freeman et al. 2000). The present study cannot determine whether hyper-stressed subjects are prone to develop Ménière's disease or whether Ménière's disease leads to stress in patients. Clearly the association between vestibular dysfunction and stress is likely to have underlying neurophysiological mechanism based on central connections beween the inner ear and autonomic nervous system (Baloh 1998; Horner et al. 2001).

Dopamine agonist therapy (bromocriptine) is well known to reduce the size of prolactinomas as well as normalize prolactin levels (Biller et al. 1999). Several lines of research suggest that dopamine has a protective role on cochlear (Eybalin 1993) and vestibular (Petrosini and Dell'Anna 1993) function. Future research should be aimed at determining the effect of dopamine agonist treatment on symptoms of Ménière's disease before surgery.

\section{REFERENCES}

Andersson G, Hägnebo C, Yardley L (1997): Stress and symptoms of Ménière's disease: A time-series analysis. J. Psychosomatic Res 43:595-603

Baloh RW (1998): Vertigo. Lancet. 352:1841-1846

Biller BM, Luciano A, Crosignani PG, Molitch M, Olive D, Rebar R, Sanfilippo J, Webster J, Zacur H (1999): Guidelines for the diagnosis and treatment of hyperprolactinemia. J Reprod Med 44(Suppl. 12):1075-1084

Blagoveshchenskaia NS, Leushkina LN (1988): Otoneurological symptomatology in tumors of the hypophysis with marked extrasellar growth. Zh. Vopr Neirokhir Im N N Burdenko 2:24-28
Committee on Hearing and Equilibrium. Guidelines for the diagnosis and evaluation of therapy in Ménière's disease (1995): Otolaryngol. Head Neck Surg. 113: 181-85.

Dominguez Ugidos LJ, Martinez Subias J, Urpegui Garcia A, Sancho Serrano E, Alfonso Collado JI, Valles Varela H (1998): Invasive giant prolactinoma. Acta Otorrinolaringol Esp 49:156-158

Eybalin M (1993): Neurotransmitters and neuromodulators of the mammalian cochlea. Physiol Rev 73:309-373

Freeman ME, Kanyicska B, Lerant A, Nagy G (2000): Prolactin: structure, function, and regulation of secretion. Physiol Rev 80:1523-1631

Horner KC, Giraudet F, Lucciano M, Cazals Y (2001): Sympathectomy improves the ear's resistance to acoustic trauma - could stress render the ear more sensitive? Eur J Neurosci 13:405-408

Fowler EP, Zeckel A (1952): Psychosomatic aspects of Ménière's disease. J Amer Med Assoc 148:1265-1268

Hoffman RM, Einstadter, D., Kroenke, K (1999): Evaluating Dizziness. Amer J Med 107:468-478

Moss-Morris R, Petrie KJ (1999): Link between psychiatric dysfunction and dizziness. Lancet 353:515

Paparella MM (1991): Methods of diagnosis and treatment of Ménière's disease. Acta Otolaryngol (Suppl. 485):108119

Petrosini L, Dell'Anna ME (1993): Vestibular compensation is affected by treatment with dopamine active agents. Arch Ital Biol 131:159-171

Schaller B, Kirsch E, Tolnay M, Mindermann T (1998): Symptomatic granular cell tumor of the pituitary gland: case report and review of the literature. Neurosurgery 42:166-170

Yardley L, Burgneay J, Nazareth I, Luxon L (1998): Neurootological and psychiatric abnormalities in a community sample of people with dizziness: a blind, controlled investigation. J Neurosurg Psychiatry 65:679-684

Yardley L, Nazareth I, Luxon L (1999): Psychiatric dysfunction and dizziness. Lancet. 353:2069 